\title{
BRUE: Un nuevo término y enfoque que podría mejorar nuestra práctica
}

\author{
BRUE: a new term and approach that could improve our practice
}

En la historia de la medicina existen múltiples ejemplos de definiciones o términos que a través de su asociación con enfoques y prácticas modificaron los cuidados de la salud y posiblemente mejoraron los resultados. Entre ellos podemos nombrar el testículo agudo, el abdomen agudo quirúrgico y el síndrome metabólico.

El término ALTE o evento de aparente amenaza a la vida, establecido por un consenso de expertos en 1986 se originó para resolver los inconvenientes con la denominación "síndrome de muerte súbita frustra o abortada" utilizada hasta ese momento, por no contar esta con evidencia que la relacionara con el síndrome de muerte súbita del lactante (SMSL).

Los eventos de ALTE pueden darse en vigilia o sueño y epidemiológicamente su mayor incidencia ocurre a menor edad, de una a tres semanas antes que la del SMSL.

Se definió al ALTE como aquel episodio inesperado y brusco que alarma al observador y representa para éste una situación de muerte inminente o real. Se caracteriza por la combinación de algunos de los siguientes signos: pausa respiratoria, ahogo o arcada, cambio de color (cianosis, palidez o rubicundez) $\mathrm{y}$ alteraciones en el tono muscular.

Una de las conclusiones de un trabajo nuestro publicado en 1995, cuya última corrección recuerdo con agrado fue realizada por el Dr. Carlos Gianantonio, fue que el ALTE no constituía un diagnóstico en sí mismo, sino simplemente una forma de presentación clínica. ${ }^{1}$

La difusión del acrónimo y sus derivaciones prácticas generaron inicialmente una mejora en los procesos diagnósticos, diferenciándose por un lado el ALTE menor o mayor según los requerimientos de estimulación o reanimación cardiovascular para modificar la evolución de dicho evento y por otro, según el diagnóstico final en idiopático y ALTE secundario a diversas patologías. ${ }^{1-3}$

Con el transcurso de los años, diferentes consensos reforzaron la necesidad de una adecuada historia clínica y un examen físico cuidadoso para avanzar selectivamente con un plan de estudios coherente basado en la experiencia clínica y para los casos graves. ${ }^{3}$
Sin embargo, la conducta médica muchas veces se inclinó a realizar una cascada de pruebas diagnósticas incluyendo la hospitalización del paciente, a pesar de que esto podría generar un riesgo innecesario y en muchas ocasiones era poco probable que condujera a un diagnóstico tratable.

La definición de ALTE generó incertidumbre en los profesionales por definir de manera imprecisa al evento, al incluir en la misma la impresión subjetiva del observador relacionado al riesgo de vida o sensación de muerte inminente. Dicha impresión provocó una respuesta asistencial y diagnóstica muchas veces excesiva y basada más en una actitud defensiva que en el conocimiento científico, evidenciándose de esa manera lo inadecuado del término elegido.

Recientemente, la Academia Americana de Pediatría (AAP) publicó una nueva guía de práctica clínica que recomienda la sustitución del término ALTE con un nuevo término, BRUE (del inglés "Brief Resolved Unexplained Events") o en español, eventos breves, resueltos e inexplicados. ${ }^{4}$

Los autores definen BRUE como un acontecimiento observado en niños menores de 1 año de edad, repentino y breve (de menos de un minuto de duración), resuelto en el momento de la consulta, caracterizado por al menos uno de los siguientes signos: cianosis o palidez, respiración irregular, ausente o disminuida, marcado cambio en el tono muscular (hiper- o hipotonía) o alteración del nivel de capacidad de respuesta.

La propuesta actual también agrega que un evento se denomina BRUE sólo cuando no hay una explicación para el mismo después de realizar una adecuada anamnesis y examen físico.

Se revisó de manera muy detallada por parte del subcomité de ALTE de la Academia Americana de Pediatría la evidencia científica desde 1970 a 2014 para desarrollar las primeras recomendaciones para el manejo de los lactantes con un BRUE (eventos breves, resueltos e inexplicados).

Los pacientes menores de un año que se presentan con un BRUE se clasifican como pacientes de bajo o alto riesgo sobre la base de la historia y el examen físico. 
La guía ofrece recomendaciones para los BRUE de bajo riesgo de recurrencia y sin patología subyacente que, en niños cumpliendo los criterios específicos, nos podrían permitir un manejo más conservador. $^{4}$

A partir de esta nueva definición, en los próximos meses se consensuarán nuevas guías o posturas prácticas tanto en las sociedades científicas como en los diversos ámbitos de asistencia para la aproximación al niño con dichos eventos. Este cambio nos acercará posiblemente a una medicina de mejor calidad, centrada en el niño y su familia, y que reduzca las intervenciones innecesarias y costosas.

Dr. Manuel Rocca Rivarola Servicio de Pediatría Departamento Materno Infantil Hospital

Universitario Austral http:/ /dx.doi.org/10.5546/aap.2016.506

Texto completo en inglés: http:/ / dx.doi.org/10.5546/aap.2016.eng.506

\section{REFERENCIAS}

1. Rocca Rivarola M, Jenik A, Kenny P, Agosta G, et al. Evento de aparente amenaza a la vida. Experiencia de un enfoque pediátrico interdisciplinario. Arch Argent Pediatr 1995;93(2):85-91.

2. Kahn A, Rocca Rivarola M. ¿Qué es un evento de aparente amenaza a la vida (ALTE)? Arch Argent Pediatr 2001;99(1): 77-9.

3. Kahn A. Recommended clinical evaluation of infants with an apparent life-threatening event. Consensus document of the European Society for the Study and Prevention of Infant Death, 2003. Eur J Pediatr 2004;163(2):108-15.

4. Tieder JS, Bonkowsky JL, Etzel RA, Franklin WH, et al. Brief Resolved Unexplained Events (Formerly Apparent LifeThreatening Events) and Evaluation of Lower-Risk Infants: executive summary. Pediatrics 2016;137(5):e20160591. 